\title{
Erratum zu: Entwicklung und Regionalökonomie in der Wirtschaftsförderung
}

\section{Erratum zu: \\ Jörg Lahner \\ Entwicklung und Regionalökonomie in der Wirtschaftsförderung, DOI 10.1007/978-3-658-13936-0_2}

Liebe Leserin, lieber Leser,

vielen Dank für Ihr Interesse an diesem Buch. Leider haben sich trotz sorgfältiger Prüfung Fehler eingeschlichen, die uns erst nach Drucklegung aufgefallen sind. Die nachfolgenden Korrekturen wurden jetzt ausgeführt.

Im Original waren die Literaturverweise in Kapitel 2 nicht immer korrekt angegeben. Darüberhinaus wurde Abb. 2.11 durch eine aktuelle Version ersetzt.

Die Online-Version des aktualisierten originalen Kapitels finden Sie unter:

DOI 10.1007/978-3-658-13936-0_2 
Region

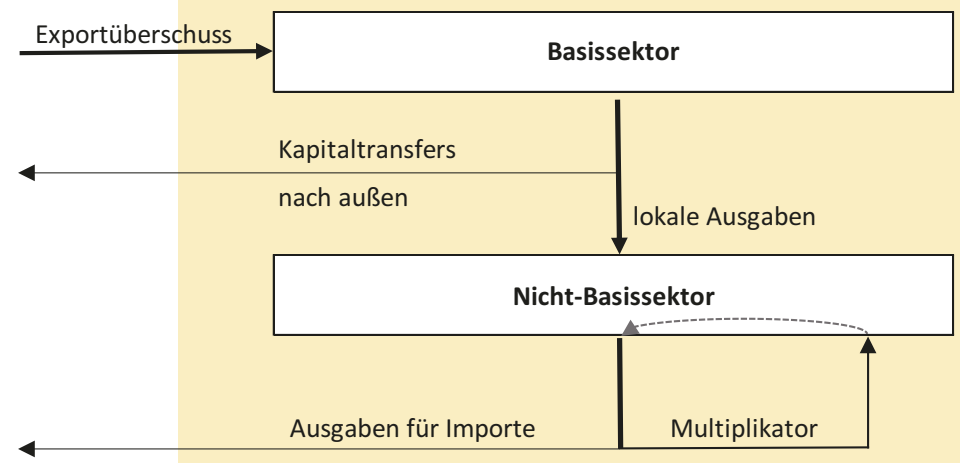

Abb. 2.11 Sektoren und Kapitalströme im Exportbasis-Ansatz (eigene Darstellung) 